\title{
Anterior decompression and fusion for ossification of the posterior longitudinal ligament of the upper thoracic spine causing myelopathy: using the manubrium splitting approach
}

\author{
Y Fujimura, Y Nishi, M Nakamura, Y Toyama and N Suzuki \\ Department of Orthopaedic Surgery, School of Medicine, Keio University, 35 Shinanomachi, Shinjuku-ku, Tokyo, 160 \\ Japan
}

\begin{abstract}
The effectiveness and problems associated with the operation of anterior decompression and fusion using the manubrium splitting approach for thoracic myelopathy due to ossification of the posterior longitudinal ligament (OPLL) of the upper thoracic spine carried out in nine patients was investigated. They were followed up for 1 year or more following the operation.

The severity of the thoracic myelopathy was evaluated using the Japanese Orthopaedic Association score, and the surgical outcome was evaluated using recovery rates. This study includes investigation of the surgical outcome and of any postoperative complications, and radiographic observation of bony union and the progression of OPLL within the area of the anterior decompression.

The caudal limit of the anterior decompression achieved by splitting the manubrium was the T3 vertebral body. A recovery rate of $71 \%$ was achieved during an average follow-up period of 35 months. Only one transient recurrent nerve palsy, and in another patient cerebrospinal fluid leakage occurred as postoperative complications. Radiographic examinations confirmed bony union in all of the patients, and there was no instance of spinal canal stenosis caused by progression of the OPLL within the area of the anterior decompression. Anterior decompression and fusion by splitting the manubrium was an effective surgical procedure for OPLL of the upper thoracic spine, to achieve a good outcome, however, the extent of anterior decompression was limited.
\end{abstract}

Keywords: ossification of the posterior longitudinal ligament (OPLL); thoracic myelopathy; upper thoracic spine; manubrium splitting approach; anterior decompression and fusion

\section{Introduction}

Ossification of the posterior longitudinal ligament (OPLL) of the thoracic spine occurs most frequently in the upper to mid-thoracic spine, but is clinically less frequent than in the cervical spine. ${ }^{1-3}$ However, thoracic OPLL leads to severe thoracic myelopathy, and surgical treatment becomes necessary because conservative treatment is ineffective. ${ }^{2,4}$ Anterior decompression is considered as a rational surgical procedure because thoracic myelopathy due to OPLL is caused by a ventral involvement of the spinal cord. ${ }^{5-13}$ However, an anterior decompression to treat upper thoracic OPLL has not been routinely used because there can be many problems associated with it, such as the difficulty of the surgical technique and the limitation of the extent of decompression. ${ }^{7,11,12,14}$

Since 1980, the authors have used anterior decompression and fusion through a manubrium splitting approach as the surgical treatment for upper thoracic OPLL. The objectives of this study were to

Correspondence: Y Fujimura clarify the effectiveness and any problems associated with this approach by analyzing the outcome of procedure and noting any complications.

\section{Materials and methods}

The subjects of this study were nine patients with myelopathy due to upper thoracic OPLL treated by the operation of anterior decompression and fusion using the manubrium splitting approach during a period 1980 to 1994, and followed up for 1 or more years. There were six males and three females. Ages at time of operation ranged from 32 to 64 (average: 48). The manubrium splitting approach was performed in eight cases, and a two-staged operation combining the manubrium splitting and an extrapleural approach was performed in one patient. However, combined operations to treat OPLL at other sites of the spine were performed in three patients. Prior to anterior decompression and fusion to treat upper thoracic OPLL, one patient was treated by a cervicothoracic posterior decompression procedure, one by a thoracic 
Table 1 Surgical cases of manubrium splitting approach for OPLL of the upper thoracic spine

\begin{tabular}{|c|c|c|c|c|c|c|c|c|c|}
\hline Case & $\begin{array}{c}\text { Age } \\
\text { (years) }\end{array}$ & Sex & $\begin{array}{l}\text { Level } \\
\text { distribution } \\
\text { of OPLL }\end{array}$ & $\begin{array}{l}\text { Previous } \\
\text { decompressive } \\
\text { surgery }\end{array}$ & $\begin{array}{c}\text { Extent of anterior } \\
\text { decompression } \\
\text { and fusion (manubrium } \\
\text { splitting approach) }\end{array}$ & $\begin{array}{l}\text { Preoperative } \\
\text { JOA score } \\
\text { (points) }\end{array}$ & $\begin{array}{l}\text { Postoperative } \\
\text { JOA score } \\
\text { (points) }\end{array}$ & $\begin{array}{l}\text { Recovery } \\
\text { rate }(\%)\end{array}$ & $\begin{array}{l}\text { Follow up } \\
\text { period } \\
\text { (months) }\end{array}$ \\
\hline 1 & 32 & M & $\mathrm{C} 2-\mathrm{T} 7$ & \multirow{3}{*}{$\mathrm{T} 5-7(\mathrm{~A})$} & $\mathrm{T} 1-3$ & 3 & 7 & 50 & 49 \\
\hline 2 & 43 & M & $\mathrm{C} 2-\mathrm{T} 2, \mathrm{~T} 4-8$ & & $\mathrm{C} 7-\mathrm{T} 2$ & 6 & 11 & 100 & 116 \\
\hline 3 & 64 & $\mathrm{~F}$ & $\mathrm{C} 3-\mathrm{T} 3, \mathrm{~T} 5-7$ & & $\mathrm{~T} 1-3$ & 5 & 9 & 67 & 18 \\
\hline 4 & 48 & M & $\mathrm{T} 1-3, \mathrm{~T} 5-6$ & \multirow[t]{2}{*}{$\begin{array}{c}\mathrm{T} 5-7(\mathrm{~A}) \\
\mathrm{C} 3-\mathrm{T} 4(\mathrm{P})\end{array}$} & $\mathrm{T} 1-3$ & 6 & 10 & 80 & 26 \\
\hline 5 & 44 & $\mathrm{~F}$ & $\mathrm{~T} 1-6, \mathrm{~T} 8-9$ & & $\begin{array}{c}\text { T1 }-3 \\
\text { T3 }-5 \\
\text { (extrapleural approach) }\end{array}$ & 2 & 9 & 78 & 28 \\
\hline 6 & 46 & M & $\mathrm{T} 1-3, \mathrm{~T} 7-8$ & \multirow{5}{*}{$\mathrm{C} 3-\mathrm{T} 6(\mathrm{P})$} & $\mathrm{T} 1-3$ & 3 & 10 & 88 & 24 \\
\hline 7 & 57 & M & $\mathrm{C} 3-\mathrm{T} 2$ & & $\mathrm{C} 7-\mathrm{T} 2$ & 5 & 9 & 67 & 20 \\
\hline 8 & 54 & $\mathrm{~F}$ & $\mathrm{C} 2-\mathrm{T} 6$ & & $\mathrm{C} 7-\mathrm{T} 2$ & 4 & 7 & 43 & 21 \\
\hline 9 & 40 & M & $\mathrm{T} 1-6$ & & $\mathrm{~T} 1-3$ & 5 & 9 & 67 & 14 \\
\hline Mean & \multicolumn{2}{|c|}{$47.7 \pm 9.6$} & & & & $4.3 \pm 1.4$ & $9.0 \pm 1.3$ & $71.1 \pm 17.8$ & $35.1 \pm 31.9$ \\
\hline
\end{tabular}

(A): anterior decompression and fusion, (P): posterior decompression. Mean: Mean \pm standard deviation
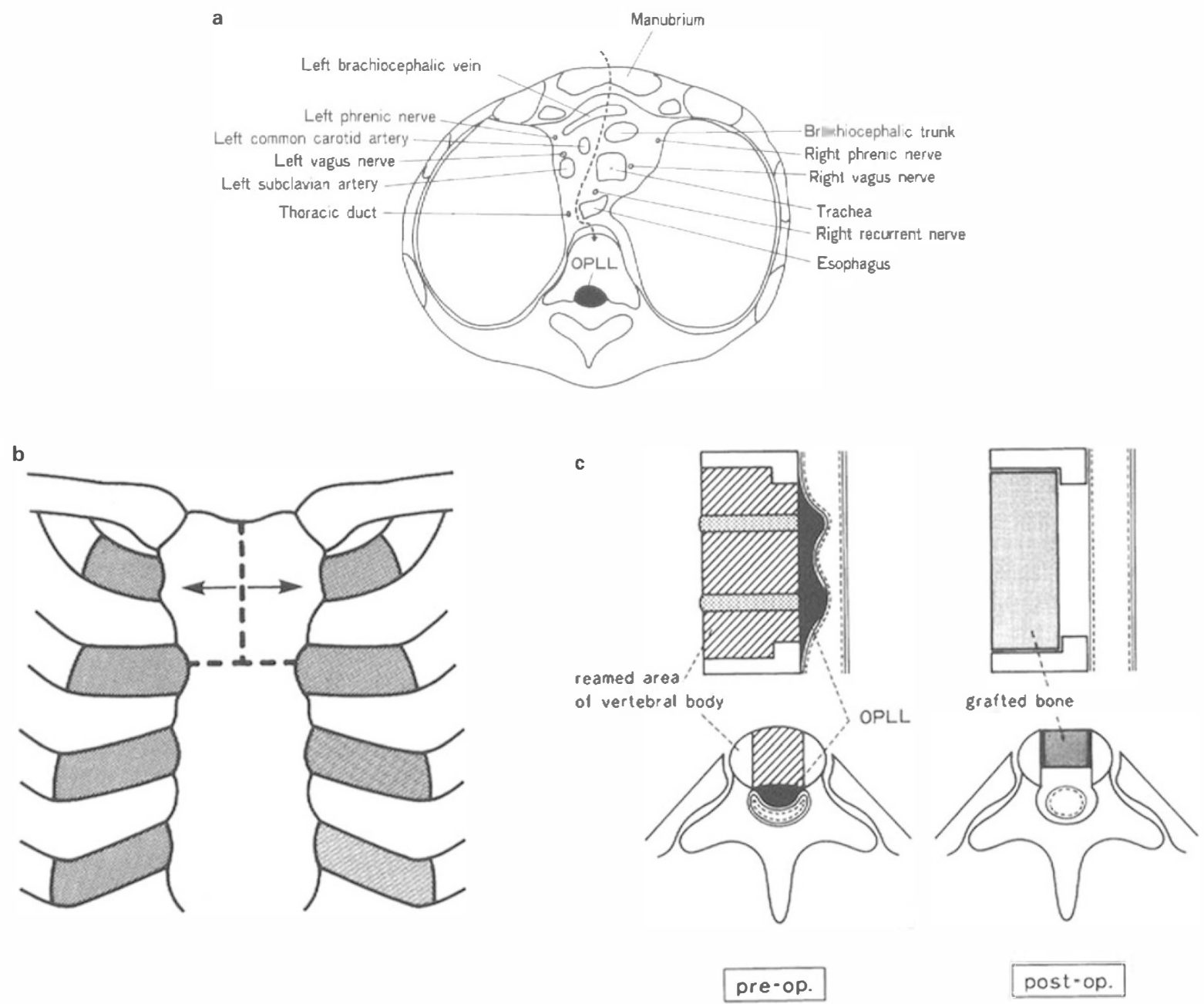

Figure 1 Schematic illustration of the operation of anterior decompression and fusion for OPLL of the upper thoracic spine using the manubrium splitting approach. (a) The manubrium splitting approach at the level of T2. (b) After transverse section of the sternomanubrial symphysis, the manubrium is split. (c) For OPLL of the upper thoracic spine cranial to the T3 vertebral body, the middle two-thirds of the involved vertebral body is planed away, and OPLL is further planed thin and removed. Upon completion of the anterior decompression, an anterior bony fusion is performed using an iliac crest bone graft strut 
Table 2 Evaluation system for thoracic myelopathy (Japanese Orthopaedic Association score)

\begin{tabular}{ll}
\hline Category & Score (point) \\
\hline A. Lower extremity motor function & \\
$\quad$ Unable to stand up or walk by any means & 0 \\
$\quad \begin{array}{l}\text { Unable to walk without a cane or other } \\
\text { support on the level }\end{array}$ & 1 \\
$\quad$ Walks independently on the level but needs & \\
$\quad$ support on stairs & 2 \\
$\quad$ Capable of fast walking but clumsily & 3 \\
$\quad$ Normal & 4 \\
B. Sensory function & \\
I. Lower extremity & 0 \\
$\quad \begin{array}{l}\text { Apparent sensory loss } \\
\text { Minimal sensory loss }\end{array}$ & 1 \\
$\quad$ Normal & 2 \\
II. Trunk & 0 \\
$\quad$ Apparent sensory loss & 1 \\
$\quad$ Minimal sensory loss & 2 \\
$\quad$ Normal & \\
C. Bladder function & 0 \\
$\quad$ Urinary retention and/or incontinence & 1 \\
$\quad$ Sense of retention and/or dribbling & \\
$\quad$ and/or thin stream & 2 \\
$\quad$ Urinary retardation and/or pollakiurua & 3 \\
$\quad$ Normal &
\end{tabular}

Total for normal patient $=11$

Recovery rate $(\%)=\frac{\text { postoperative score }- \text { preoperative score }}{11-\text { preoperative score }} \times 100$

anterior decompression and fusion by an extrapleural approach, and a third patient with a combination of these procedures. The follow-up period ranged from 14 to 116 months (average: 35) (Table 1).

We modified the scoring system for cervical myelopathy established by the Japanese Orthopaedic Association (JOA) by excluding the items concerning the upper extremities in order to evaluate the severity of the thoracic myelopathy (Table 2). The normal score for the evaluation of thoracic myelopathy is 11 points (JOA score). The recovery rate was calculated from the preoperative and postoperative JOA scores, and was used for the evaluation of the surgical outcome. We considered the outcome to be excellent, good, fair, unchanged, or worse when the recovery rate was $75-$ $100 \%, 50-74 \%, 25-49 \%, 0-24 \%$, or less than $0 \%$ respectively.

\section{Indications}

Surgical indications were determined by considering the severity of the thoracic myelopathy, in particular, the degree of lower extremity motor dysfunction and urinary bladder dysfunction. JOA scores of two or less for lower extremity motor function, or two or less for bladder function were considered to be absolute indications for surgery. The preoperative JOA scores were 2-6 points (average: 3.4 ) for the nine cases of upper thoracic OPLL.
Surgical approach and technique of anterior decompression and fusion

For the manubrium splitting approach, the skin incision was started from the inferior one third portion of the anterior medial margin of the left sternomastoid muscle and was extended along the midline of the sternum to the level of the third rib. After making a transverse section of the sternomanubrial symphysis and a longitudinal section of manubrium, a direct midline approach to the spine was carried out. The anterior aspects of the lower cervical and upper thoracic spine were exposed by avoiding the esophagus and trachea on the right side, and the brachiocephalic artery and vein on the caudal aspect. The middle two-thirds of the involved vertebral bodies were resected using a steel pneumatic cutting burr. Then using a diamond burr the OPLL was planed thin and was removed. In the case of adhesion of OPLL to the dura mata, the anterior floating method of OPLL was carried out to separate the dura matter. On completion of the anterior decompression, an anterior bony fusion was performed using an iliac crest bone graft strut (Figure 1). The sternum was reconstructed by binding with AO wire; however, more recently, titanium Songer cable has been used.

\section{Post-operative care}

After the operation the patients were confined to their beds in a supine position. Three weeks after the operation, they were provided with a plastic cervical orthosis and were permitted to leave their beds. The orthosis was used for 12 to 16 weeks.

\section{Results}

The extent of anterior decompression achieved by the manubrium splitting approach was T1-T3 in six patients and C7-T2 in three. The caudal limit of the anterior decompression achieved by this approach was T3 vertebral body (Figure 2). Anterior decompression and fusion performed from T1-T5 in one patient was accomplished using a combination of the manubrium splitting and extrapleural approaches in a two-staged operation (Figure 3). The time required to perform the decompression on an average of three vertebral bodies was in the range of $4 \mathrm{~h}$ and $12 \mathrm{~min}$, to $5 \mathrm{~h}$ and $40 \mathrm{~min}$ (average: $4 \mathrm{~h}$ and $42 \mathrm{~min}$ ). Intraoperative blood loss were 789 to $1686 \mathrm{~g}$ (average: $1090 \mathrm{~g}$ ).

The preoperative JOA score, $4.3 \pm 1.4($ mean $\pm \mathrm{SD}$ ) points, improved to $9.0 \pm 1.3$ points postoperatively; the average recovery rate was $71 \%$. The outcome at the time of follow-up was excellent in four patients, good in four, and fair in one patient. No patient's neurological condition was unchanged or worse (Table 1).

Solid bony union was confirmed, and late fatigue fracture of grafted bone did not occur. Also, restenosis of the spinal canal by progression of OPLL was not found within the area of the anterior decompression. 


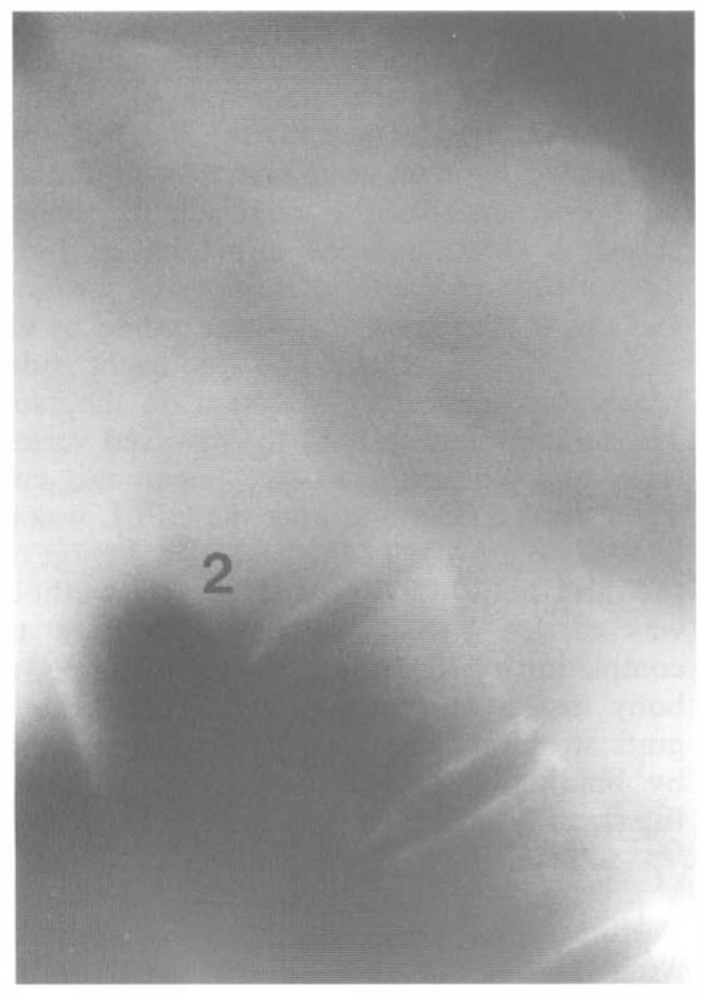

c

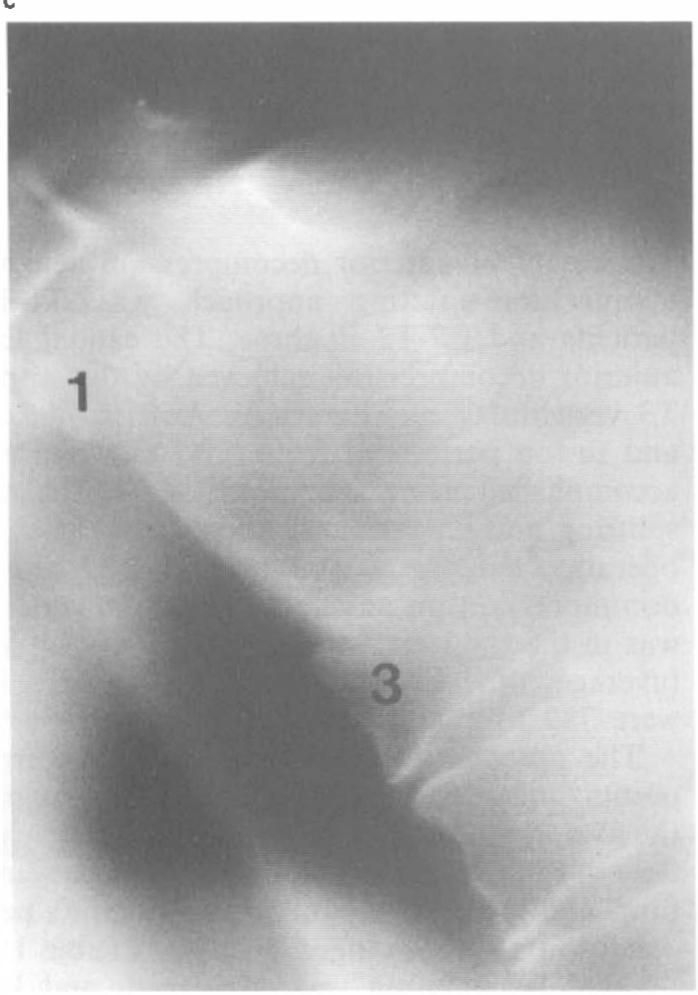

b

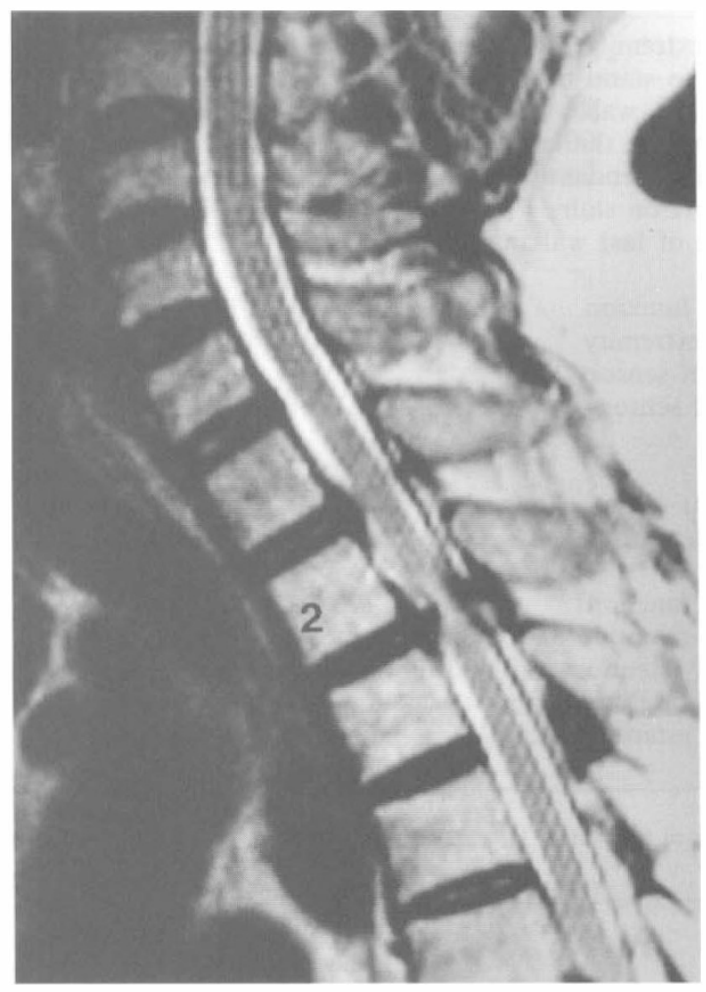

d

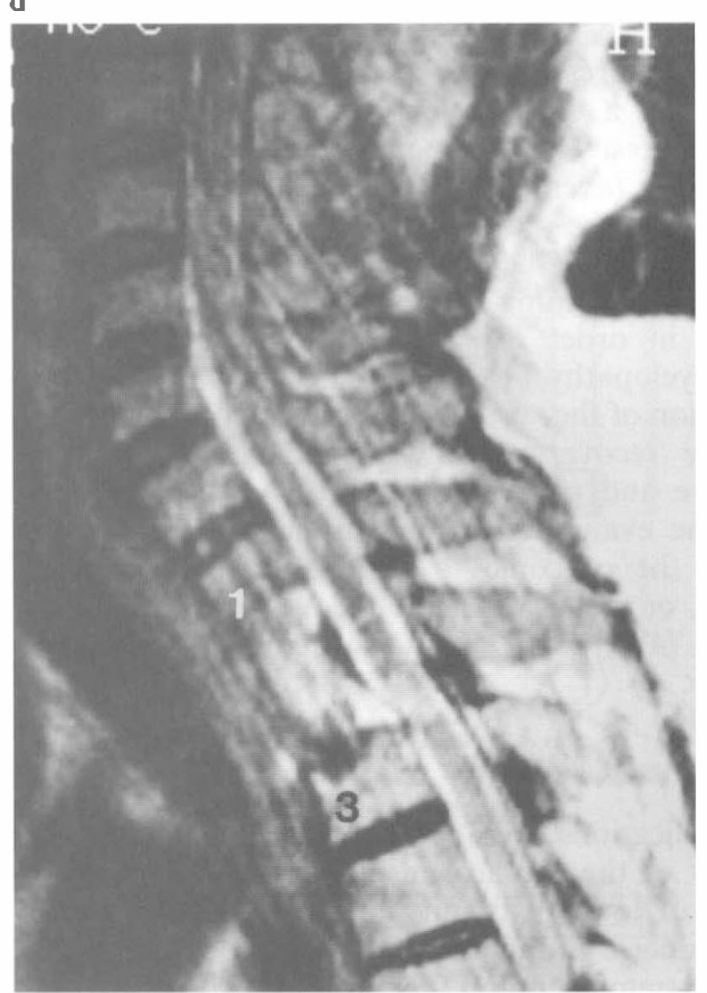

Figure 2 Case 4. 48 year old male with OPLL of T1-3 and T5-6. Anterior decompression and fusion of T1-3 was performed using the manubrium splitting approach. (a) Preoperative lateral tomogram. (b) Preoperative T2 weighted sagittal MRI. (c) Postoperative lateral tomogram. (d) Postoperative T2 weighted sagittal MRI 


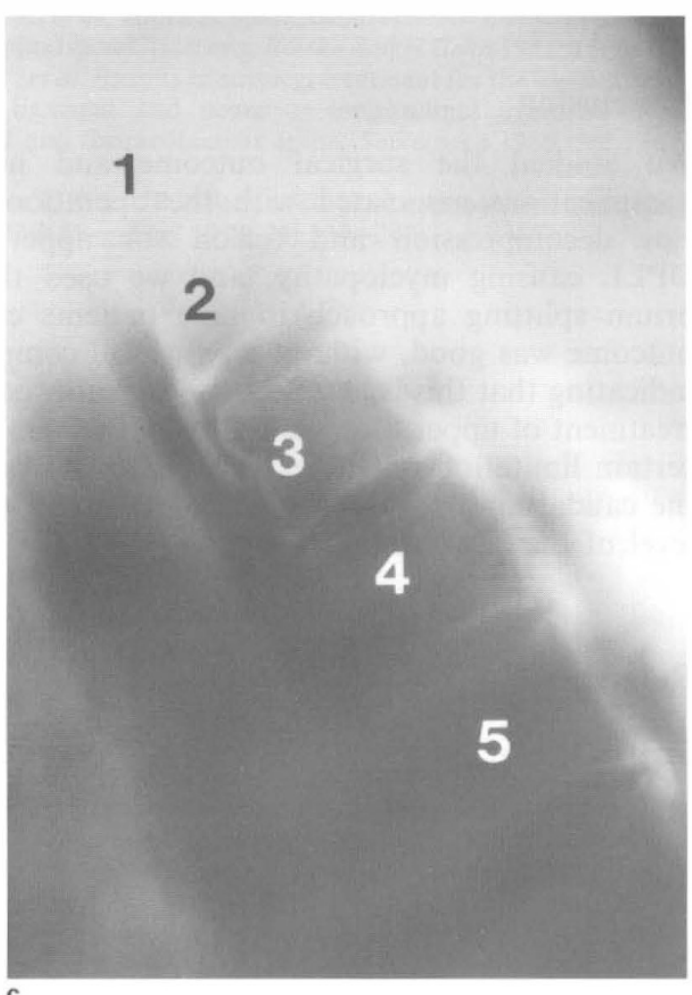

c

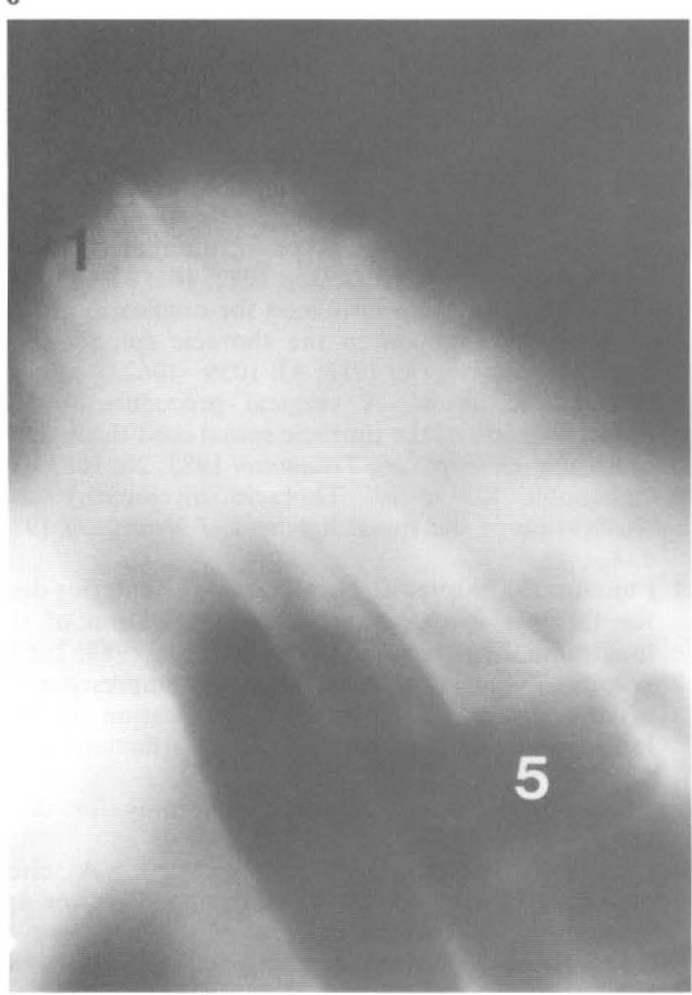

b
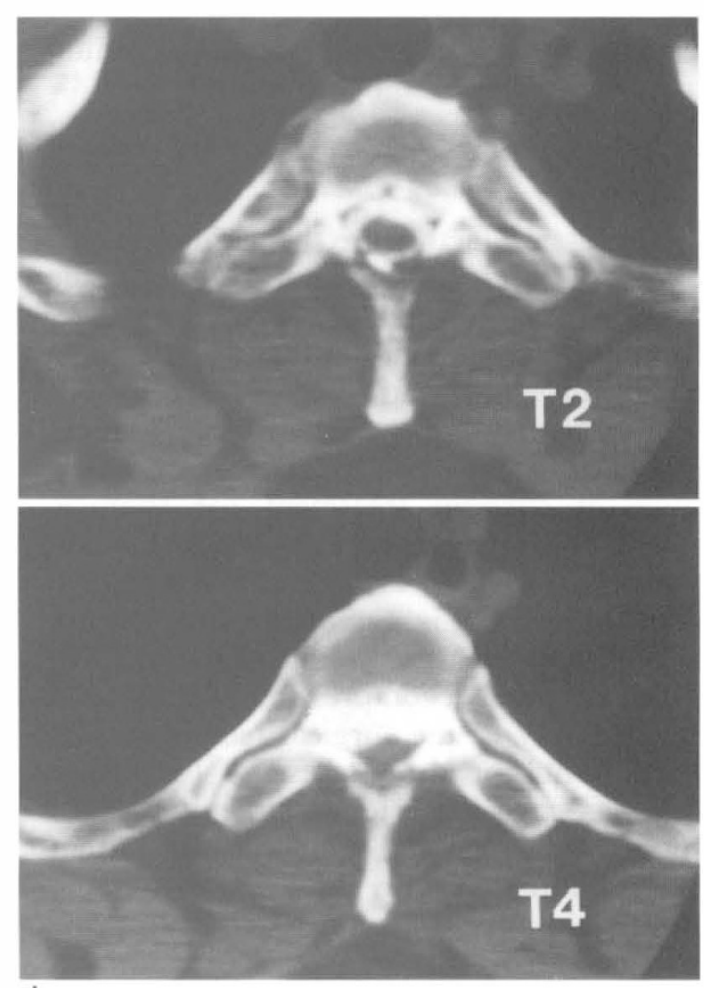

d
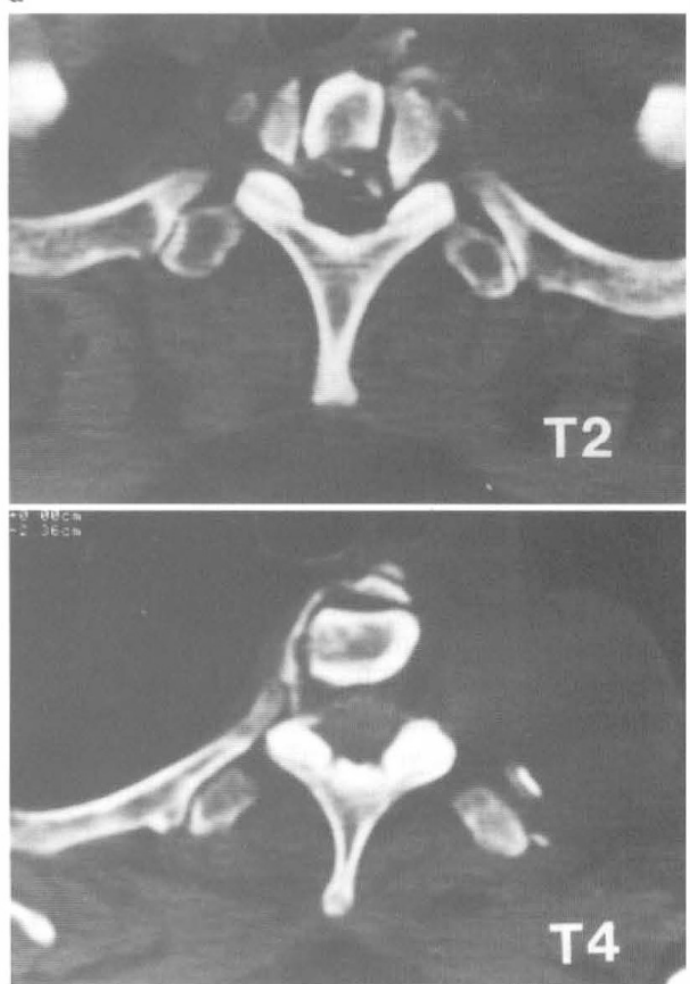

Figure 3 Case 5. 44 year old female with OPLL of T1-6 and T8-9. Anterior decompression and fusion of T1-T5 was performed using combination of the manubrium splitting approach and the extrapleural approach. (a) Preoperative lateral tomogram. (b) Preoperative CTM at the level of T2 and T4. (c) Postoperative lateral tomogram. (d) Postoperative CT at the level of T2 and T4 
Recurrent nerve palsy and leakage of cerebrospinal fluid occurred in one case each as postoperative complications. The palsy recovered within 10 weeks after the operation, and leakage of cerebrospinal fluid ceased within 3 weeks after the operation.

\section{Discussion}

Static spinal compression factors are the major cause of thoracic myelopathy due to thoracic OPLL, where the role of dynamic factors are minimal, if indeed they exist, because of the anatomical stability of the thoracic spine because of the rib cage. Therefore, conservative treatment cannot be expected to be effective, and surgical treatment is indicated if thoracic myelopathy occurs.

The objective of surgical treatment for thoracic OPLL is complete decompression of the affected spinal cord. This can be achieved by an anterior decompression, in which the OPLL is removed. However, a posterior decompression was frequently performed, ${ }^{15-19}$ and an anterior decompression was limited because of the difficulty of the surgical technique. ${ }^{5} 13$ In particular, an anterior decompression for upper thoracic OPLL was considered to be difficult because of the limitations of the surgical approach and extent of decompression, and therefore there are not many published reports on this treatment. ${ }^{7,12,14}$ At the present, with the advances in spine surgery an anterior approach to all levels of the thoracic spine is practical, ${ }^{20-22}$ anterior decompression is the rational surgical procedure for thoracic OPLL, with the anterior compressing lesion of the spinal cord. Also, the effects of posterior decompression are unreliable because of the physiological kyphosis of the thoracic spine, and there may also be deterioration of the thoracic myelopathy, because kyphosis of the thoracic spine may occur postoperatively, thus posterior decompression should be avoided. . $^{-13}$

The surgical outcome of anterior decompression and fusion by manubrium splitting approach for upper thoracic OPLL was investigated in this study. The objectives of this study were to clarify the effectiveness and note any problems associated with this surgical procedure. The outcome, according to clinical and radiolographic evaluation, was good, and postoperative complications were quite minimal, and there were no neurological complications. The results were almost satisfactory. However, the caudal limit for anterior decompression was the T3 vertebral body, and the extent of decompression was restricted. Although complications occurred in only two cases, the fact that any complication occurred indicates that prevention of complications is important when approaching the upper thoracic spine, by a thorough knowledge of the local anatomy of the superior mediastinum and by expert surgery. Extreme care is required when handling the fragile thoracic cord, and forced removal of the ossification should be avoided, and the anterior floating method of OPLL ${ }^{23}$ should be selected for anterior decompression when the OPLL and dura matter adhere together, in order to prevent neurological complications or leakage of cerebrospinal fluid.

\section{Conclusion}

We studied the surgical outcome and noted any complications associated with the operation of anterior decompression and fusion for upper thoracic OPLL causing myelopathy, and we used the manubrium splitting approach in nine patients cases. The outcome was good, without any critical complications, indicating that this is an effective surgical procedure for treatment of upper thoracic OPLL. However, there was certain limitation on the extent of decompression, and the caudal limit for anterior decompression was at the level of the T3 vertebral body.

\section{References}

1 Terayama K. Ossification of the posterior longitudinal ligament of the spine. J Jpn Orthop Assoc 1976; 50: 415-442.

2 Tsuyama N, Kurokawa T. Statistical analysis of the patients with ossification of the posterior longitudinal ligament of the thoracic and lumbar spines. Rinsho Seikei Geka 1977; 12: 337-339.

3 Tsuyama N. Ossification of the posterior longitudinal ligament of the spine. Clin Orthop 1984; 184: $71-84$.

4 Kurokawa T, et al. Diagnosis of the thoracic spinal canal stenosis and the evoked spinal cord action potential measurement. Rinsho Seikei Geka 1981; 16: $32-42$.

5 Ohtani K, et al. Anterior decompression for ossification of the posterior longitudinal ligament of the thoracic spine. Rinsho Seikei Geka 1977; 12: 353-359.

6 Fujimura Y, et al. Surgical treatment for thoracic myelopathy due to spinal canal stenosis. Rinsho Seikei Geka 1981; 16: 51-62.

7 Ohtani K, et al. Anterior surgical decompression for thoracic myelopathy as a result of ossification of the posterior longitudinal ligament. Clin Orthop 1982; 166: $82-88$.

8 Hanai $\mathrm{K}$, et al. Decompression for ossification of the posterior longitudinal ligament in the thoracic spine using the lateral approach. Seikeigeka 1982; 33: 1059-1062.

9 Ohtsuka K, et al. A surgical procedure for the anterior decompression of the thoracic spinal cord through the posterior approach. Orthop Surg Traumatol 1983; 26: 1083-1090.

10 Yonenobu $\mathrm{K}$, et al. Thoracic myelopathy secondary to ossification of the spinal ligament. J Neurosurg 1987; 66: $511-$ 518.

11 Fujimura Y, Satomi K, Hirabayashi K. Anterior decompression for thoracic myelopathy due to ossification of the posterior longitudinal ligament. Spine Spinal Cord 1989; 2: 671-677.

12 Tomita K, et al. Circumspinal decompression for thoracic myelopathy due to combined ossification of the posterior longitudinal ligament and ligamentum flavum. Spine 1990; 15: $1114-1120$.

13 Yonenobu K, et al. Lateral rhachotomy for thoracic spinal lesions. Spine 1990; 15: $1121-1125$.

14 Kataoka O, Sho T, Nishibayashi Y. A circumferential decompression of spinal cord through posterior approach for myelopathy due to ossification of the posterior longitudinal ligament on the upper thoracic spine. Seikeigek a 1989; 40: 669 675.

15 Imai $\mathrm{K}$, et al. Clinical evaluation of ossification of the posterior longitudinal ligament of the thoracic spine. Rinsho Seikei Geka 1977; 12: $340-344$.

16 Murakami Y, et al. Posterior decompression for thoracic myelopathy due to ossification of the posterior longitudinal ligament. Rinsho Seikei Geka 1977; 12: 345-352. 
17 Miyazaki K, et al. Surgical treatment for ossification of the posterior longitudinal ligament of the thoracic spine. Rinsho Seikei Geka 1977; 12: 360 - 367.

$18 \mathrm{Kaneda} \mathrm{K}$, et al. Thoracic spinal canal stenosis due to ossification of the spinal canal ligament. Rinsho Seikei Geka 1981; 16: 63-74.

19 Sakou T, et al. Results of surgical treatment for the ossification of yellow ligament and posterior longitudinal ligament of the thoracic and thoracolumbar spine. Seikeigeka 1985; 36: $1367-$ 1375.

20 Cauchoix J, Binet JP. Anterior surgical approaches to the spine. Ann R Coll Surg Engl 1957; 21: 237-243.
21 Hodgson AR, et al. Anterior spinal fusion: the operative approach and pathological findings in 412 patients with Pott's disease of the spine. Br J Surg 1960; 48: 172-178.

22 Fielding JW, Stillwell WT. Anterior cervical approach to the upper thoracic spine: a case repoprt. Spine 1976; 1: $158-161$.

23 Yamaura I. Anterior floating method for ossification of the posterior longitudinal ligament. Rinso Seikei Geka 1983; 18: $855-868$. 